\title{
Workplaces of the Future - How are they Studied? A Literature Study of Foresight and Delphi Methods
}

\author{
I Susanna Toivanen \\ PhD, Centre for Health Equity Studies, Stockholm University/Karolinska Institute, Sweden
}

\section{Introduction}

W

orking life conditions have changed dramatically during the last few decades with a comprehensive impact on how daily work is organised in the workplace (Marklund \& Härenstam, 2010; Lundberg \& Cooper, 2011). This development highlights the question whether future challenges that influence workplaces could be met more efficiently by using futures studies methodology in working life research. A workplace, in general terms, may be defined as a place or physical location of work or employment where work is done, depending on the sector and the industry, and the nature of the core business activity. A broader definition captures aspects of modern working life such as knowledge workers, telework, flexible work arrangements and global networks. Therefore, a more suitable definition would be that a workplace is an environment that enables work to be done (de Kerchove \& Pollack, 2010). Thus, a modern workplace may be defined in terms of its physical, social and virtual aspects.

Based on two recent research reports, the aim of this paper is to exemplify how workplaces of the future are studied in contemporary literature (Håkansta et al., 2009; Regus \& JB Associates, 2009). The aim is also to determine the main challenges for workplaces of the future caused by changing working life, and to compare whether the conclusions drawn in the two reports differ. The first report is a Foresight study performed by European working life researchers in a project financed by the European Commission with the aim of establishing cooperation channels for research in the area of work-related innovations (Håkansta et al., 2009). The report summarises findings from a two-day Foresight seminar about future workplaces. The second report focuses on business leaders' opinions about workplaces of the future. The study uses the Delphi method of interviewing experts and was conducted by Regus, a leading provider of workplace solutions, in collaboration with research consultants JB Associates (Regus \& JB Associates, 2009). The present paper starts with a short introduction into futures research. Thereafter the two reports on workplaces of the future are reviewed and discussed.

\section{Futures research}

Regarding research into future, the main challenge is how to define the future. The future, from the Latin futurus, is something that is "about to be" and that normally includes an expectation of advancement or progressive development occurring at a later time (Merriam-Webster, 1993). "The world of the future is in our making. Tomorrow is now.” Eleanor Roosevelt once said, and stressed that current populations and decision- 
makers have a huge impact on and responsibility for the state and development of the future (Roosevelt, 1963). One could also try to define the future by reasoning about its essential characteristics (Heinonen, 2010); for instance, that the future evolves in front of us. Something that was said a second ago belongs to the past and something that is going to be said in a second belongs to the future until it is expressed. As wide and endless as the sea, the future holds various possibilities and directions for development. But the sea is also deep, and only a few future possibilities reach the surface and become realised. Moreover, the future may be visualised and anticipated by using futures research methodology (Glenn et al., 2009).

People have always planned for their future, and in the early 1960s research methodology started to develop, and futures research was established as a research field of its own (Myrdal, 2008). Forecasts about the future in contemporary literature are categorised in several ways. Bergman (2010) and colleagues present a typology based on whether the forecast makes truth claims and/or explanatory claims about the future state of events. A combination of these two dimensions gives four specific types of forecasts: predictions (both truth claims and explanatory claims), prognoses (truth claims, but not explanatory claims), science fiction (explanatory claims, but not truth claims), and utopias or dystopias (neither truth claims nor explanatory claims). In addition to different types of forecasts, the research into future also differs regarding methodological issues. The term futures studies was used to indicate the uncertainty associated with forecasting the future and that there are several possible developments for the future state of events (Myrdal, 2008). Some researchers recommend another type of distinction between futures research and futures studies (Håkansta et al., 2009). While the first category comprises empirically-based prognoses, such as the future development of populations and labour markets based on demographic analyses, the second category contains qualitative methods including various scenario techniques and Delphi methods. Foresight, on the other hand, seems to have a special position in futures studies. Foresight is neither a prophecy nor a prediction, but a method that aims to build the future, not to predict it (European Comission et al., 2005).

\section{Foresight and Delphi methods}

Futures research methodology offers a variety of ways of exploring future possibilities, and Foresight and Delphi are commonly used methods within the field (Glenn et al., 2009). The European Commission's Joint Research Centre (JRC) explains that "Foresight arises from a convergence of trends underlying recent developments in the fields of 'policy analysis', 'strategic planning' and 'future studies'. It brings together key agents of change and various sources of knowledge in order to develop strategic visions and anticipatory intelligence" (European Comission et al., 2005). Thus, Foresight provides input into strategy and policy planning, as well as into collective strategic actions. The four main characteristics of Foresight are that it is (1) an action-orientated method that supports actors to actively shape the future, it is (2) open to alternative futures that can be shaped to some extent by the actions and decisions taken today, it is (3) participatory as it is not performed by a small group of experts or academics but involves a number of different actors concerned with the issue in focus, and it is (4) multidisciplinary as it provides an approach that aims to capture realities in their totality, and therefore is 
not limited to one perspective or academic discipline. The Delphi method is based on the collection of expert knowledge. Several types of experts may be interviewed, such as experts in a field of research ("the Oracle of Delphi"), youngsters (who are the future), or decision makers (who decide about the future). The three main features of Delphi are that the process is based on (1) anonymity; (2) iteration, meaning that the process includes several rounds of interviews; and (3) feedback, meaning that the anonymous material is sent back to all the participants in the study for further comment in order to reach consensus. There are also studies that combine the Foresight and Delphi approaches (NEW OSH ERA, 2008).

\section{How To Study Workplaces Of The Future}

In order to get a comprehensive view of the research into workplaces of the future, a systematic literature review is warranted. Such a review is usually based on peer reviewed scientific articles, but it may also include so called grey literature such as popular science publications (Petticrew \& Roberts, 2006). Information is gathered through extensive searches in databases and by consulting experts in the field. The present paper is part of a systematic literature review performed by the author within an ongoing research project of future workplaces. The two reports that are discussed below are chosen by the author as examples of the current state of the interdisciplinary research field of future workplaces.

\section{The reviewed studies}

The reviewed research reports on workplaces of the future apply Foresight and the Delphi methods, respectively. In addition to methodology, the reports also differ in whose vision they present. The Foresight report summarises findings from a two-day Foresight workshop held in Stockholm 2008 gathering 25 European researchers who participated in the WORK-IN-NET project financed by the European Commission (Håkansta et al., 2009). The workshop was initiated and organised by the Swedish Council for Working Life and Social Science (FAS) which invited WORK-IN-NET partner organisations to contribute to the workshop with short Foresight reports written by national experts. These Foresight reports were presented and discussed at the workshop. The research report (142 pages) is divided into two parts, a summary from the workshop written by FAS representatives Carin Håkansta and Kenneth Abrahamsson, and a second part comprising the five original short Foresight reports from different regions of Europe. The authors conclude that the purpose of the workshop was not optimally met as only a few of the partner organisations presented their own futures studies. Also, more attention was paid to general methods and strategies of futures studies, employment and broader conditions of work than to the workplaces of the future as such.

The second report is a brief publication of 27 pages written in "consultants' language" with catchy headings and easily accessible information (Regus \& JB Associates, 2009). The report was presented by Regus, a leading provider of workplace solutions "that allow individuals and companies to work however, wherever, and whenever they need to" (www. regus.com). The research was conducted and the report was written by John Blackwell, 
a British research consultant and business transformer (www.jbassociates.uk.com). The focus is on business leaders' opinions about workplaces of the future. The research uses the Delphi method and it is part of an ongoing annual interview study of 1,130 business leaders worldwide regarding workplace challenges. The business leaders represent large and small organisations from different industry sectors and from both established and emerging economies. Each of the six chapters concludes with recommendations on how organisations can move forward toward a Workplace of the Future.

\section{Future working life}

Both reports state globalisation and geopolitics, climate change and environmental issues, rapid technological development, a need for flexibility on several levels, and the composition and diversity of the future workforce as the main challenges of working in the future. The reports stress the need for managing an aging and diverse workforce as well as highly educated staff. Social justice, shared values and sustainable actions are expected to become more important for employees in the future.

The European researchers discuss that rapid economic and cultural globalisation together with the shift from an energy-based industrial economy to a service and knowledge-based economy will contribute to the emergence of a global "knowledge society" (Håkansta et al., 2009). Yet, globalisation in terms of the international ownership of corporations may introduce conflict between the international culture of the new enterprise and local corporate cultures. Climate change is challenging our modern life style and consumer behaviour both at work and in private life. Aging populations, together with late labour market entrance for young citizens, and early retirement of some workers are among the main challenges for future labour forces and working life. As to the development of industries, some visions for the European economy indicate that agricultural activities will experience a recovery, the manufacturing industry will continue to decline, and the service industry will continue to dominate. The transition from manufacturing industries to service industries is sometimes assumed to involve the introduction of new and high skilled jobs. This in turn would increase the demand for highly educated employees that the companies have to compete for to employ and retain.

The business leaders who are interviewed in the Delphi study identified some additional challenges for future working life (Regus \& JB Associates, 2009). They perceive a demand for agility and a significant workplace change ahead that their organisations need to capture and manage. Increasing collaboration is viewed as one of the most important aspects of changing working life. Demanding teamwork, both internal and external, is viewed as an opportunity to differentiate workplace models and make them more collaborative. The challenge is, therefore, how to attract and retain increasingly informed and socially aware staff. In 2004, the business leaders' focus was mainly on market factors, such as customer trends, market shifts, and competitors' actions. External factors in terms of socio-economics, geopolitics, and environmental issues were seen as less influential. In 2008, market factors were still on the agenda, but people's skills were considered just as important, and environmental issues demanded twice as much attention as they had done in the past. Thus, market factors and people's skills, as well as environmental issues and rapid technological development seem to have a large impact on future working life according to business leaders. 


\section{Future workplaces}

Both reports put forward that the future brings huge changes that workplaces need to take into account and adapt to. However, what the changes in fact consist of is not entirely clear. One could interpret the "demand for agility", as expressed by the business leaders, as the need for flexibility on several levels. First, flexibility may concern the built environment (the possibility to swiftly modify the physical workplace) as certain companies may be short-lived or volatile. Second, flexibility on an organisational level incorporates companies' ability to promptly adapt to the demands of the economy. Third, flexibility may also include adjustable workplace arrangements according to the needs of a diverse workforce. For instance, at certain periods in life, employees may need more flexibility in order to optimise their work and private life balance. Elderly or disabled employees may also benefit from flexible arrangements regarding workplace and working time. Organisational trust is a prerequisite for such workplace flexibility. To conclude, both reports stress the need for preparing for future challenges on several levels including global, local and workplace levels.

In addition to pressure from globalisation, labour migration, and aging workforces, the challenges for future workplaces include increasing workload and stress at work, and new demands supported by management ideals focusing on efficiency and productivity (Håkansta et al., 2009). There is a risk that the position of relatively weak groups in the labour market - women, foreign-born, and disabled persons - will further weaken in the future which may lead to increasing labour market segmentation. Such a development would contribute to increasing social inequalities in health between different groups in the labour market and workplaces. Management of an aging and diverse workforce as well as highly educated staff is an issue that future workplaces need to consider and take proper action for. With regards to the psychosocial work environment, work intensity will grow, and bullying and work-related depression will be increasingly present in future workplaces. Risks in the physical work environment will persist. As to the intensity of work, as well as increasing flexibility in work arrangements, some research suggests that new drugs will be developed that will facilitate and improve performance and productivity (Håkansta et al., 2009). However, despite increasingly demanding and intensive workplaces, workers of the future would seem to have a different agenda and set of values. For them, time will be more important than money, family will be more important than work, and enjoyment and fun will be essential both at work and leisure. Sustainable actions and operations both at work and in private life will be valued and ideological radicalism will increase.

The business leaders discuss that working outside the workplace becomes even more common in the future, the distinction between workplaces and other places where work is accomplished becomes less clear (Regus \& JB Associates, 2009). Also, the division between work life and leisure time will be less evident with the potential risk that people will engage in work around the clock, seven days a week. Control of time usage and trust within organisations are therefore among the main prerequisites for such a development within workplaces. Workers are viewed as the capital that employers and technology will support. A workplace of the future is pictured by the business leaders as "hungry for change" meaning that the workplace is capable of changing and adapting swiftly and successfully according to future demands. The workplace is innovative to the extent that it even surpasses the expectations of an increasingly demanding staff. 
Innovations are created that make both staff and organisations more successful. The globalised working life provides an arena for future workplaces that enables them to stay globally connected and to take advantage of the global economy. Being hungry for change also entails present business models and outmoded habits being questioned and replaced with new ones. The workplace of the future reflects genuine concern for society in all actions and decisions.

\section{Concluding Comments}

This short literature review was based on two recent reports that focus on workplaces of the future. Important information on future workplaces is, therefore, most likely lacking and for a comprehensive enquiry a systematic literature review is warranted. However, these two reports give a glimpse of the ongoing debate and research in the field of future workplaces. The main feature of the field is that it includes many voices, those of researchers, consultants, business people, thinkers, and to a lesser extent, employees.

There are a few important differences between the two reports regarding whose visions are presented - researchers versus business leaders. The two reports also differ in the scientific methods they apply - Foresight versus the Delphi approach. Moreover, the tone of the two reports is remarkably different. Although worth reading, the report provided by researchers may be viewed as slightly premature (summarising workshop findings). On the other hand, the report conducted by consultants is somewhat persuasive and delivers a vision of the workplace of the future that is hardly questioned and the recommendations sometimes sound like "quick fixes".

Despite these differences, similar basic assumptions appear in both reports. Future workplaces are diverse, they operate in a changing global world and they need to take concrete action in preparing themselves for future challenges at global, local and workplace levels. How these preparations are conducted in the best way is a key issue for social partners in the labour market and an important topic for further research. Perhaps, as stated by one of the European researchers, new forms of knowledge production are needed. The field would benefit from knowledge production that integrates enterprises, associations and communities as research partners. Such knowledge production would ease the diffusion of research findings into daily work practice and create strong learning networks to support the development of workplaces of the future.

\section{Acknowledgement}

This work was supported by Stiftelsen Riksbankens Jubileumsfond(RJ),grant no. RMP10-1127:1.

\section{References}

Bergman, A., Karlsson, J. C., \& Axelsson, J. (2010). Truth claims and explanatory claims--An ontological typology of futures studies. Futures, 42(8), 857-65.

de Kerchove, G., \& Pollack, R. (2010). Workplace. PdK Consulting. http://www.pdkconsulting.com/workplacedefinition/ 15 June 2010. 
European Comission, Joint Reserach Centre, \& Institute for Prospective Technological Studies (2005). The FOR-LEARN Online Foresight Guide. European Commission - JRC IPTS. http://forlearn.jrc.ec.europa.eu/guide/0_home/index.htm 6 June 2010.

Glenn, J. C., Gordon, T. J., \& Millennium Project. (2009). Futures research methodology -

Version 3.0. Washington, DC: American Council for the United Nations University, The Millennium Project.

Heinonen, S. (2010). Att förutse framtiden kan ge konkurrensfördelar i utveckling av kontorsarbetsplatser. Helsinki: NCC.

Håkansta, C., Abrahamsson, K., \& WORK-IN-NET. (Eds.) (2009). Workplaces of the future. WORK-IN-NET Foresight Seminar held in Stockholm, Sweden, 4-5 September 2008. Stockholm/Bonn: WORK-IN-NET.

Lundberg, U., \& Cooper, C. L. (2011). The science of occupational health: stress, psychobiology, and the new world of work. Chichester: Wiley-Blackwell.

Marklund, S., \& Härenstam, A. (Eds.) (2010). The dynamics of organizations and healthy work. Växjö: Linnéuniversitetet, Institutionen för samhällsvetenskaper.

Merriam-Webster, I. (1993). Merriam-Webster's collegiate dictionary. Springfield, MA: Merriam-Webster, Inc.

NEW OSH ERA (2008). A Foresight study on future challenges of OSH research. Dortmund: Federal Institute for Occupational Safety and Health.

Petticrew, M., \& Roberts, H. (2006). Systematic reviews in the social sciences : a practical guide. Malden, Ma: Blackwell Pub.

Regus, \& JB Associates (2009). The Workplace of the Future. London: Regus.

Roosevelt, E. (1963). Tomorrow is now. New York: Harper \& Row. 